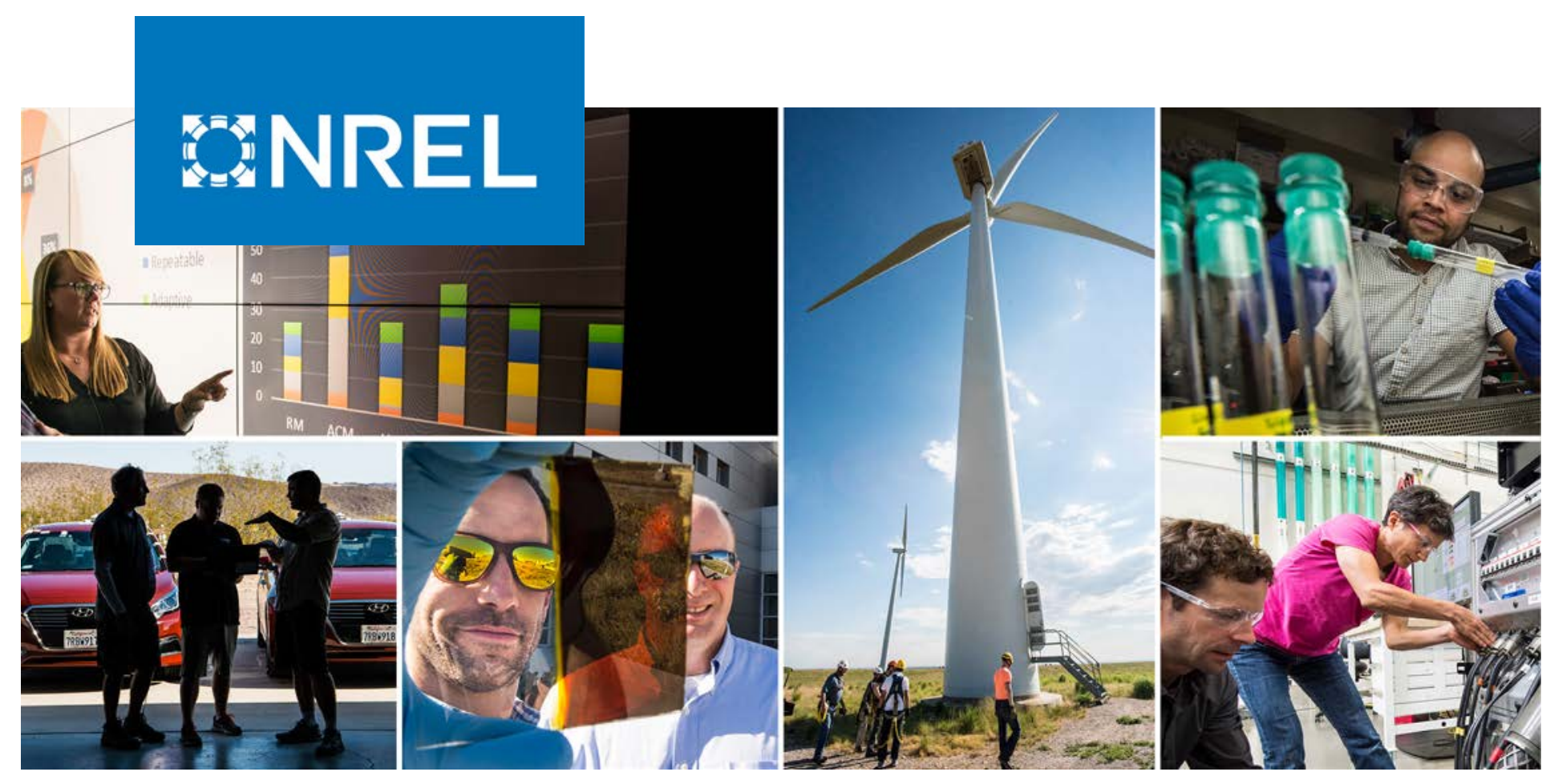

\title{
Background Information on the Power Quality Requirements in IEEE Std 1547-2018
}

Michael Ingram, Rasel Mahmud, and David Narang

National Renewable Energy Laboratory

NREL is a national laboratory of the U.S. Department of Energy

Office of Energy Efficiency \& Renewable Energy

Operated by the Alliance for Sustainable Energy, LLC

This report is available at no cost from the National Renewable Energy Laboratory (NREL) at www.nrel.gov/publications.
Technical Report

NREL/TP-5D00-78751

October 2021 


\section{GNREL}

\section{Background Information on the Power Quality Requirements in IEEE Std 1547-2018}

Michael Ingram, Rasel Mahmud, and David Narang

National Renewable Energy Laboratory

\section{Suggested Citation}

Ingram, Michael, Rasel Mahmud, and David Narang. 2021. Background Information on the Power Quality Requirements in IEEE Std 1547-2018. Golden, CO: National Renewable Energy Laboratory. NREL/TP-5D00-78751.

https://www.nrel.gov/docs/fy22osti/78751.pdf.

NREL is a national laboratory of the U.S. Department of Energy Office of Energy Efficiency \& Renewable Energy Operated by the Alliance for Sustainable Energy, LLC

This report is available at no cost from the National Renewable Energy Laboratory (NREL) at www.nrel.gov/publications.

Contract No. DE-AC36-08GO28308
Technical Report NREL/TP-5D00-78751 October 2021

National Renewable Energy Laboratory 15013 Denver West Parkway Golden, CO 80401 303-275-3000 • www.nrel.gov 


\section{NOTICE}

This work was authored by the National Renewable Energy Laboratory, operated by Alliance for Sustainable Energy, LLC, for the U.S. Department of Energy (DOE) under Contract No. DE-AC36-08GO28308. Funding provided by U.S. Department of Energy Office of Energy Efficiency and Renewable Energy Solar Energy Technologies Office Award Number 34808. The views expressed herein do not necessarily represent the views of the DOE or the U.S. Government.

This report is available at no cost from the National Renewable Energy Laboratory (NREL) at www.nrel.gov/publications.

U.S. Department of Energy (DOE) reports produced after 1991 and a growing number of pre-1991 documents are available free via www.OSTI.gov.

Cover Photos by Dennis Schroeder: (clockwise, left to right) NREL 51934, NREL 45897, NREL 42160, NREL 45891, NREL 48097, NREL 46526.

NREL prints on paper that contains recycled content. 


\section{Preface}

The revised Institute of Electrical and Electronics Engineers (IEEE) Standard for Interconnection and Interoperability of Distributed Energy Resources with Associated Electric Power Systems Interfaces (IEEE Std 1547-2018), was published in April 2018. This standard is one of the foundational documents in the United States needed for integrating distributed energy resources (DERs), including solar energy systems, and energy storage systems with the electric distribution grid.

The revised standard contains 11 chapters (clauses) and 8 annexes that comprise 136 pages. The revision is significantly different from the 2003 version, and it contains new concepts and new technical requirements. Each clause specifies information or requirements that apply to certain aspects that are important to the interconnection of DERs to the electric power system. Implementing the requirements necessitates a careful study of the underlying technical concepts and requires appropriate information to calculate relevant settings and configurations.

Various stakeholders have different roles in implementing the standard, and portions of the standard are directed toward a specific audience who must possess specialized information and technical training to use and apply the requirements.

This document provides informative material on the requirements related to electrical power quality in IEEE Std 1547-2018, with the intent to equip the reader with basic knowledge and background information to improve understanding and use of the requirements specified.

Note that this document reflects the authors' interpretations, which in some instances might differ from one person to another; therefore, this work is intended to supplement the existing and growing body of knowledge ${ }^{1}$ across the U.S. electric sector on the use and application of this important standard.

\footnotetext{
${ }^{1}$ Additional educational material can be found at https://www.nrel.gov/grid/ieee-standard-1547/.
} 


\section{Acknowledgments}

This material is based upon work supported by the U.S. Department of Energy (DOE) Office of Energy Efficiency and Renewable Energy (EERE) under the Solar Energy Technologies Office (SETO) Award Number 34808.

The authors are thankful for the comments from project partners and members of the review committee for this work.

The authors are also grateful to DOE EERE SETO Strategic Analysis and Institutional Support Program Manager Michele Boyd; Robert Reedy and Jeremiah Miller; and Systems Integration Program Manager Guohui Yuan for their guidance and support. We thank Peter Gotseff and Akanksha Singh for providing helpful comments on the earlier draft of the report. 


\section{List of Acronyms}

ANSI

DER

DOE

EERE

EMC

EMI

EPRI

EPS

GFO

IEC

IEEE

LRO

PCC

Plt

Pst

PV

RVC

SETO
American National Standards Institute

distributed energy resource

U.S. Department of Energy

Office of Energy Efficiency and Renewable Energy

electromagnetic compatibility

electromagnetic interference

Electric Power Research Institute

electric power system

ground fault overvoltage

International Electrotechnical Commission

Institute of Electrical and Electronics Engineers

load rejection overvoltage

point of common coupling

long-term flicker perceptibility

short-term flicker perceptibility

Photovoltaic

rapid voltage change

Solar Energy Technologies Office 


\section{Executive Summary}

Power quality is often viewed strictly from the consumers' perspective and is considered the delivery of clean and stable energy, measured in consistent voltage and current sinusoidal waveforms from the utility to the consumer. The traditional grid with large central power stations and transmission and distribution networks is a very complex system, which make it extremely difficult to ensure the delivery of quality power to the end users. The delivery of clean power to customers becomes even more complicated with the interconnection of dynamic, nonlinear loads and customer-owned inverter-based generation. Nonlinear loads and inverter-based generation can introduce distortion to otherwise consistent voltage and current sinusoidal waveforms. Further, some power quality phenomena can harm grid equipment. Therefore, power quality is a joint responsibility of all users of the electric grid.

The Institute of Electrical and Electronics Engineers Standard for Interconnection and Interoperability of Distributed Energy Resources with Associated Electric Power Systems Interfaces (IEEE Std 1547-2018) does not deal directly with power quality per se, but the requirements in the standard have a direct impact on power quality. This document presents a summary of power quality-related requirements in IEEE Std 1547-2018 as outlined in Table ES1 (Enayati 2018).

Table ES-1. How Different Power Quality Parameters Can Be Affected by IEEE Std 1547-2018

\begin{tabular}{lll}
\hline Smart Inverters... & With & How? \\
\hline Are likely to help: & $\begin{array}{l}\text { Entering service } \\
\text { Immunity to voltage } \\
\text { sags }\end{array}$ & $\begin{array}{l}\text { Expect better ramp rate and frequency control. } \\
\text { New ride-through requirements could reduce the } \\
\text { number of trips. }\end{array}$ \\
& $\begin{array}{l}\text { Avoiding high or low } \\
\text { voltage at the PCC }\end{array}$ & $\begin{array}{l}\text { Expect volt/volt ampere reactive and other reactive } \\
\text { power support modes to improve voltage regulation at } \\
\text { the PCC, especially when coordinated with other } \\
\text { voltage control elements on the feeder. }\end{array}$ \\
& $\begin{array}{l}\text { Harmonic current } \\
\text { Could lead to new } \\
\text { incompatibilities: }\end{array}$ & $\begin{array}{l}\text { Higher-order harmonics-up to } 20 \mathrm{kHz} \text { from inverter } \\
\text { switching-sometimes appear as resonances in } \\
\text { special circumstances. Prediction of these issues by } \\
\text { modeling is difficult. }\end{array}$ \\
& $\begin{array}{l}\text { Communication } \\
\text { interference }\end{array}$ & $\begin{array}{l}\text { Lack of immunity to EMI could result in failures to } \\
\text { communicate. }\end{array}$ \\
\hline
\end{tabular}

Chapter 2 of this document provides a summary of the power quality issues associated with distributed energy resources. Chapter 3 provides a discussion on power quality-related requirements in IEEE Std 1547-2018. Chapter 4 explores power quality test requirements, setting expectations, and related decisions.

The key power quality-related issues covered in IEEE Std 1547-2018 are DC injection, flicker, rapid voltage change, overvoltage, harmonics, and electromagnetic interference. Most power quality-related requirements are discussed in Chapter 7 of IEEE Std 1547-2018, whereas electromagnetic interference is discussed in Section 4.11. 


\section{Table of Contents}

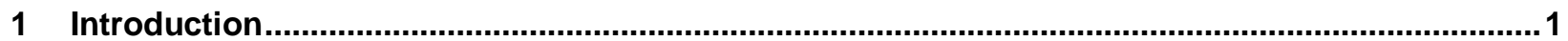

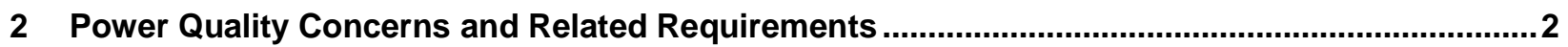

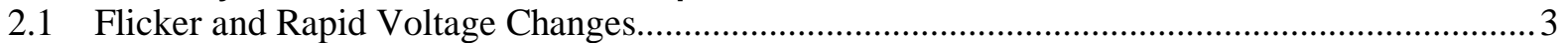

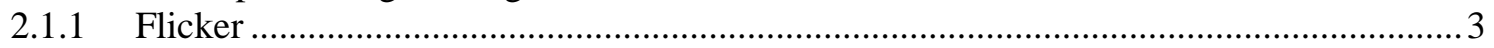

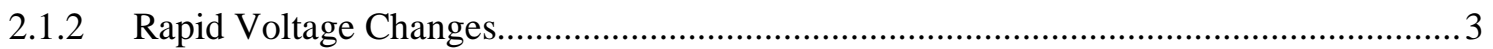

2.2 Voltage and Current Distortion (Harmonics) .............................................................................. 4

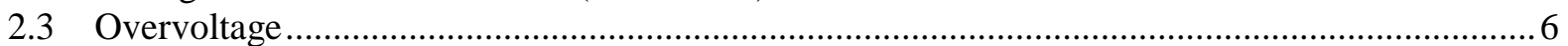

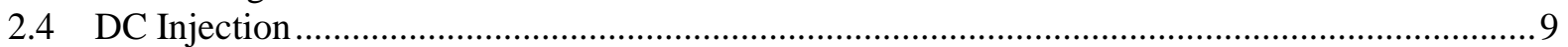

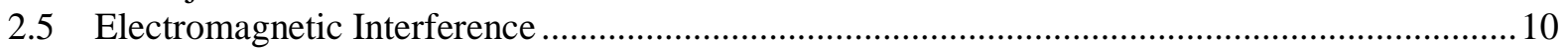

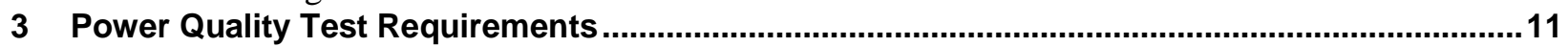

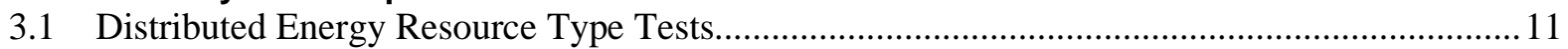

3.2 Distributed Energy Resource Evaluation and Commissioning Tests ....................................... 11

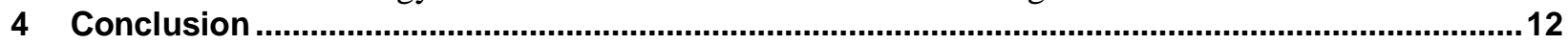

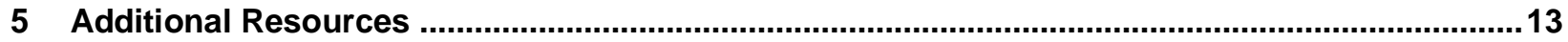

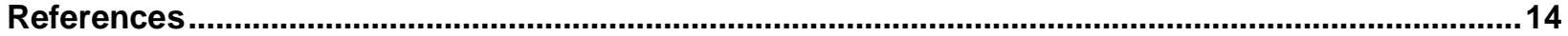




\section{List of Figures}

Figure 1. Illustrative example of signal distortion caused by high-frequency harmonics...........................5

Figure 2. Illustrative examples of different overvoltage phenomena observed in power systems ................8

\section{List of Tables}

Table 1. Acceptable RVCs for DERs at the PCC ..................................................................................

Table 2. Maximum Allowed Overvoltage Contribution by DERs ..........................................................9

Table 3. How Different Power Quality Parameters Can Be Affected by IEEE Std 1547-2018................. 12

Table 4. Relevant Standards for Power Quality Issues................................................................... 13 


\section{Introduction}

The revised Institute of Electrical and Electronics Engineers Standard for Interconnection and Interoperability of Distributed Energy Resources with Associated Electric Power Systems Interfaces (IEEE Std 1547-2018) contains 11 chapters (clauses) and 8 annexes that comprise 136 pages. Each clause specifies information or requirements that apply to certain aspects important to the interconnection of distributed energy resources (DERs) to the electric power system (EPS). The implementation of the requirements needs a careful study of the underlying technical concepts and the appropriate information that might be required to calculate various settings and configurations.

IEEE Std 1547-2018 Clause 7 specifies requirements for power quality-related phenomena with which DERs must comply. Annex G in the standard provides informative background information on power quality-related topics pertaining to DERs. Unlike the earlier version of the standard, thorough requirements are specified in IEEE Std 1547-2018 to mitigate the adverse impact on power quality by DERs.

The power quality clause is directed primarily to DER device manufacturers, ${ }^{2}$ testing agencies, ${ }^{3}$ and laboratories. Other interested parties could include commissioning agencies, electric utilities (the area electric power system operator), and DER operators.

Other stakeholders who are typically concerned with the requirements specified in IEEE Std 1547-2018 include state electric regulators, energy offices and other policymaking entities, independent system operators, solar developers and/or integrators (including distributed and utility-scale), electric transmission utilities, and regional transmission organizations.

IEEE Std 1547-2018 assumes that the reader possesses the appropriate training and experience necessary to understand and apply the stated requirements. This could include foundational electrical engineering knowledge, knowledge of the area EPS device settings, parameters and operational practices, and knowledge of general and specific DER capabilities relevant to the subject.

This document provides a high-level summary of the context and background concepts for requirements related to power quality. This document is intended as a supplement to material already published or in development. ${ }^{4}$ It is not intended as an exhaustive resource on technical implementation. Rather, topics are presented at a level appropriate to serve individuals who require an introduction or technical refresher to the material.

\footnotetext{
${ }^{2}$ Solar and other DER device manufacturers are inherently interested in the performance requirements in IEEE Std 1547-2018; however, this document focuses on the application of the standard rather than the manufacturing process of the DER device.

${ }^{3}$ The term testing agency includes entities such as nationally recognized testing laboratories.

${ }^{4}$ For example, the expected revision to IEEE Std 1547.2, Application Guide for IEEE Std 1547.
} 


\section{Power Quality Concerns and Related Requirements}

The impact of poor power quality can range from a distracting flicker of lamps to equipment failure. Many electrical equipment and processes are sensitive to power quality issues, such as small variations or brief interruptions in the supplied electric power. If these power quality issues are not properly addressed, they can result in additional cost to the customer in the form of plant or equipment downtime, equipment replacement, and lost data or work in process. There are standards to address the power quality problem in power systems, e.g., IEEE Std 1453 and International Electrotechnical Commission (IEC)/TR 61000-3-7. In addition, IEEE Std 15472018 is designed to avoid or mitigate some adverse impacts on power quality that might be caused by DERs. The broad definition of power quality — or, more specifically, a power quality disturbance - is generally accepted as any change in the power (voltage, current, or frequency) that interferes with the normal operation of electrical equipment (Dougherty and Stebbins 1997). But there is a wide range of more specific definitions for power quality. The IEEE Recommended Practice for Monitoring Electric Power Quality (IEEE Std 1159-2019) defines power quality as " $\mathrm{t}] \mathrm{he}$ concept of powering and grounding electronic equipment in a manner that is suitable to the operation of that equipment and compatible with the premise wiring system and other connected equipment" (IEEE 2019).

Note that high-resolution power quality measurement equipment is specialized and typically not permanently installed on distribution systems. Often, power quality problems are identified only after investigation by the utility in response to a customer request. In such cases, a utility worker is dispatched to the customer site to install a temporary power quality meter and record data for a sufficient amount of time to capture the disturbance. The disturbance data are required to identify the root cause of the power quality problem so that a proper solution to mitigate it can be implemented. For example, the sequence to investigate power quality issues by Hawaiian Electric is as follows:

- "Review of Electrical Disturbance Logs

- Review of the Facility's Single Line Electrical Diagram

- Site Survey by Hawaiian Electric

- Review of Equipment documentation (example: specifications, equipment manuals, operating procedures)

- Installation of Power Quality Monitoring Instruments

- Analysis of Power Quality Data" (Hawaiian Electric 2021).

Generally, power quality concerns associated with the interconnection of DERs focus on the possible impacts of variable renewable energy resources, particularly solar photovoltaics (PV) or wind generators. Voltage rise due to reverse power flow from DERs and voltage variations caused by fluctuations in wind or PV generation (i.e., due to the variability of wind or cloud movement) are two of the most prominent and potentially problematic impacts of DERs. These effects are particularly pronounced when large amounts of DERs, such as PV, are connected near the end of long and lightly loaded distribution circuits. 


\subsection{Flicker and Rapid Voltage Changes}

\subsubsection{Flicker}

Flicker is the visible change of an electric lamp's brightness, often in a cyclic pattern. IEEE defines flicker as the "subjective impression of fluctuating luminance caused by voltage fluctuations" (IEEE 2015). The original standard for measuring flicker was based on the effects of voltage fluctuations on a 60-W incandescent lamp. Flicker is not a modern phenomenon-the "GE flicker curve," the most widely adopted performance curve for flicker (IEEE 2015), was developed in the 1930s in response to certain flicker-producing electrical loads, such as arc furnaces.

Regulation mechanisms are implemented in DERs and other network assets, such as load-tap changing transformers, to adjust the network voltage and frequency within an acceptable range. High or low voltages can occur because of the fluctuations in PV output and before the regulation has a chance to respond. These voltage fluctuations can cause flicker, which can be irritating to customers and can also result in malfunctioning appliances. Because the power output of PV can fluctuate considerably and much faster than the response of traditional voltage regulation equipment, there is potential for voltage flicker when large amounts of PV are connected. An examination of data from a grid-integrated 1.41-MW PV plant at Florida International University showed that PV power plant output can adversely affect power quality by exceeding, even marginally, the permissible flicker limits according to IEEE standards (Rahman et al. 2018). A more comprehensive study by the Electric Power Research Institute (EPRI) based on five PV demonstration sites pointed out that flicker can be caused by the aggregated interactions of all fluctuating grid-connected resources, including PV and load (Shi, Key, and Huque 2019).

Table 25 in IEEE Std 1547-2018 lists the allowed DER contribution to flicker measured at the point of common coupling (PCC) for short-term flicker severity and long-term flicker severity. Individual DERs must also follow the requirement of IEC/TR 61000-3-7. The standard refers to IEEE Std 1453 and IEC/TR 61000-3-7 for requirements on the assessment and measurement of flicker. Additional equipment other than the DERs to mitigate flicker is allowed.

Power quality requirements in IEEE Std 1547-2018 are more explicit and quantitative than in prior versions, which facilitates the enforcement of the requirements with less ambiguity. For example, regarding flicker, the prior version merely stated that DERs "shall not create objectionable flicker for other customers." The update limits short-term flicker perceptibility (Pst) and long-term flicker perceptibility (Plt) contributions from DERs to specific quantitative limits based on the IEC flickermeter algorithm as defined in IEEE Std 1453-2015 (IEEE 2015). Section 7.2 of IEEE Std 1547-2018 discusses the limitations of different voltage variationsrapid voltage change (RVC) and flicker.

\subsubsection{Rapid Voltage Changes}

Both IEEE and IEC recognize that the power quality phenomena referred to as RVC might not be captured by flickermeter or steady-state measurements. RVC can manifest in either an increase or decrease in voltage, but according to IEC standards defining the phenomena, it does not exceed a 10\% change from nominal (IEC 2008). Motor starting is one well-known cause of 
RVC, and although such events typically occur infrequently, they are often sustained during several electrical cycles. Unlike flicker, RVC can manifest in physical transients in electrical loads or result in harmful incompatibilities in grid-connected equipment, such as reclosers, capacitors, and transformers.

IEEE Std 1547-2018 also places limits on intermittent, abrupt RVC (but not on infrequent distribution circuit events, such as switching, unplanned tripping, or transformer energization related to commissioning, fault restoration, or maintenance). In fact, by applying limits on the change in voltage percentage $(\Delta \mathrm{V} \%)$ and ramp rate, the requirements in the standard are more stringent than those found in IEEE Std 1453. At nominal system voltages equal to or greater than $1 \mathrm{kV}$ and less than or equal to $35 \mathrm{kV}$ (medium voltages), $\Delta \mathrm{V} \%$ shall be limited to $3 \%$ of nominal, and ramp rate shall be limited to $3 \%$ per second averaged during a period of 1 second. DERs connected at low voltages have requirements of a $5 \%$ limit for these measures.

IEEE Std 1547-2018 requires that DERs cannot create unacceptable RVC and flicker at the PCC. Acceptable RVC is defined as shown in Table 1. These limits are not intended for variations in voltage caused by slow changes in weather conditions, i.e., clouds passing or a change in wind speed. The area EPS can allow an exception to the limits considering the contribution of RVC in a particular EPS from other sources. Additional conditions of the applicability of these limits are also included in IEEE Std 1547-2018 where these limits are exempted for infrequent cases, including switching, unplanned tripping, transformer energization related to commissioning, fault restoration, and maintenance; however, these exemptions do not include frequent eventsi.e., frequent energization of the transformer, frequent switching of the capacitors, or DER misoperation.

Table 1. Acceptable RVCs for DERs at the PCC

\begin{tabular}{lll}
\hline PCC Voltage Level & Maximum Step or Ramp Change & Maximum Voltage Change Rate \\
\hline Medium voltage & $3 \%$ of nominal & $3 \%$ per second \\
Low voltage & $5 \%$ of nominal & $5 \%$ per second \\
\hline
\end{tabular}

a The changes are measured as root-mean-square voltage at the PCC.

$\mathrm{b}$ The voltage change should be computed as averaged during a period of 1 second.

Default values for flicker limits and rapid voltage change limits are preset by the DER manufacturer; however, should the need arise, the area EPS operator may specify alternate limits.

\subsection{Voltage and Current Distortion (Harmonics)}

For many utility engineers, the words power quality often invoke current and voltage harmonic distortion issues (Walling 2017). IEEE defines a harmonic as a "component of order greater than one of the Fourier series of a periodic quantity" (IEEE 2014). For example, in a 60-Hz power system, as operated in the United States, the third harmonic is $180 \mathrm{~Hz}$. Although many people visualize electrical energy as a perfect $60-\mathrm{Hz}$ sine wave, nonlinear loads distort the ideal by injecting harmonic currents. Figure 1 shows an illustrative example of signal distortion caused by high-frequency harmonics. 


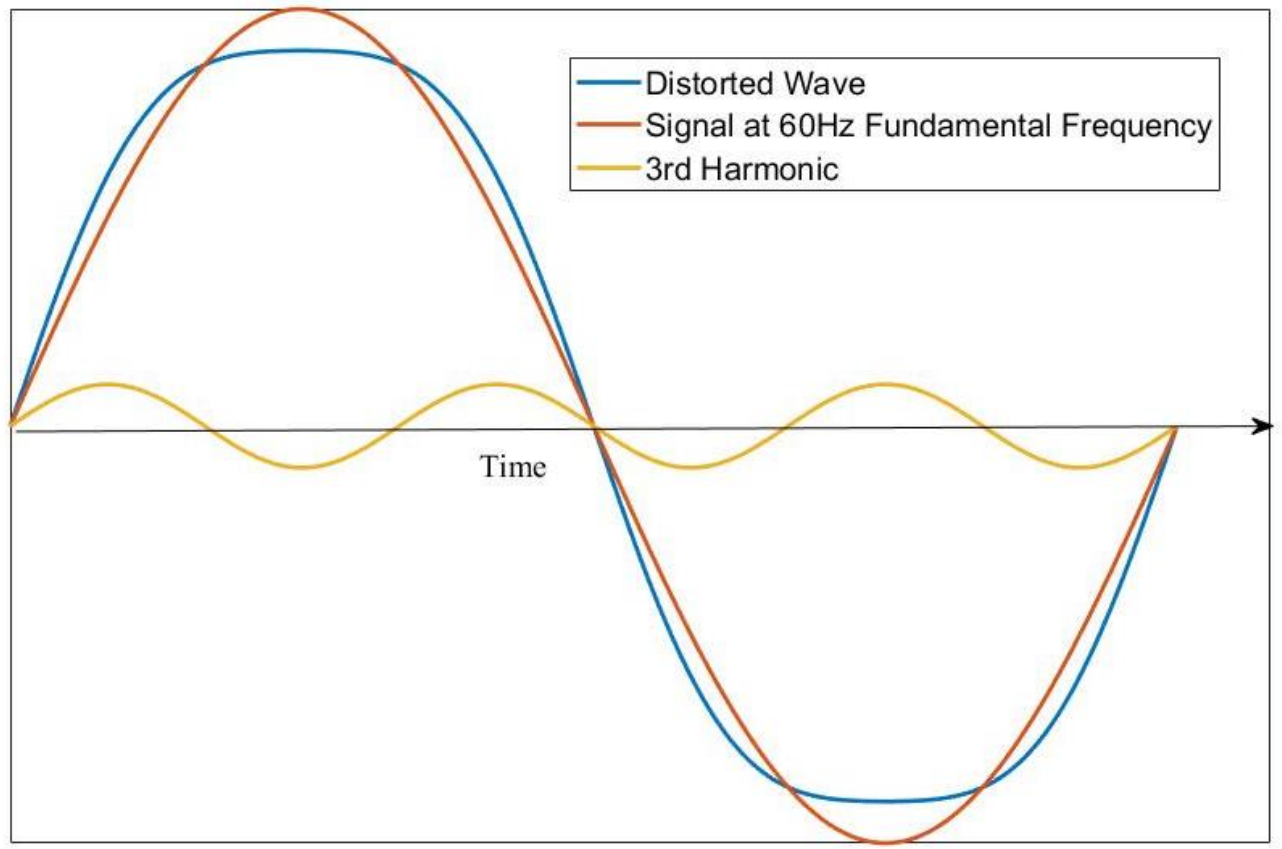

Figure 1. Illustrative example of signal distortion caused by high-frequency harmonics

Harmonic currents lead to increased electrical losses and heating in electromagnetic devices (motors, transformers, etc.) and can cause interference with communication circuits. Voltage harmonics are developed by aggregate current harmonics interacting with system and load impedances. Guidance provided by IEEE (IEE 2014) states that "managing harmonics in a power system is considered a joint responsibility involving both end-users and system owners or operators" and recommends harmonics limits for both current and voltage.

Most DERs installed today use power electronics to convert the DC from PV arrays and fuel cells, or the variable-frequency AC output of wind turbines and microturbines, to $60-\mathrm{Hz} \mathrm{AC}$. These inverters use components switching at frequencies generally on the order of a few 1,000 $\mathrm{Hz}(\mathrm{kHz})$ to synthesize a $60-\mathrm{Hz}$ voltage using pulse-width modulation. Although the pulse-width modulation process assembles an imperfect voltage, output-stage filters remove this distortion, yielding a relatively clean signal at the inverter terminals. Note that IEEE Std 1547-2018 sets limits on DER current harmonics, not voltage. The amount of harmonic current distortion is a function of the system impedance at the point of connection at the frequency of the distortion.

Endemic voltage distortion in the grid, which is typically caused by other loads (e.g., consumer electronics, variable-speed drives, compact fluorescent lamps), especially at higher penetration levels, can cause harmonic currents to flow at the point of DER connection. This complicates the field measurement of DER harmonic contributions versus background distortion from other harmonic sources. Troubleshooting cautions include (EPRI 2018):

- Limited frequency response in typical utility-grade potential transformer and current transformer devices

- Influence of area EPS background voltage distortion on DER performance

- Influence of area EPS harmonic impedances on DER performance

- Limited resolution of monitoring equipment at low levels of current or voltage. 
Note that the IEEE Recommended Practice and Requirements for Harmonic Control in Electric Power Systems (IEEE Std 519) is widely used in the utility industry and is often cited in interconnection requirements. In fact, the recommended harmonic limits specified in IEEE Std 519 were directly incorporated into the 2003 version of IEEE Std 1547. Yet, distortion limits specified in IEEE Std 1547-2018 are specified in terms of current, ${ }^{5}$ and the requirements no longer apply to only the integer harmonic orders but also to the inter-harmonic ${ }^{6}$ frequencies between the integer orders.

Maximum allowed even and odd harmonic current distortions at the reference point of applicability measured in percentage of rated current are tabulated in Table 26 and Table 27 in IEEE Std 1547-2018. The methodology of measuring harmonic and inter-harmonic values found in IEEE Std 519 is adopted in IEEE Std 1547-2018. A new term, total rated current distortion, has been introduced when specifying the harmonic limits of DERs. Total rated current distortion was introduced to capture both harmonic and inter-harmonic distortions while calculating harmonic distortion. The requirement for even-order current harmonic limits has been relaxed compared to IEEE Std 519 for higher-order (8th or higher) harmonics; however, this relaxation of limits was not applied to the 2nd harmonic because it was found that the DC offset effect (see Section 2.4) mainly originates from the 2 nd-order harmonic. The maximum allowed total rated current distortion has been set to $5 \%$ at the reference point of applicability. Conformance to the standard regarding higher-order harmonics must be confirmed using equipment designed for the frequency in question.

By mutual agreement with the utility, DERs can inject current distortion exceeding the harmonic limits specified in IEEE Std 1547-2018 if they are operated as an active filter. By injecting harmonic currents opposite to those produced by customer loads and devices, DERs can cancel or reduce distortions - an effect potentially beneficial to the utility system.

\subsection{Overvoltage}

Steady-state voltage performance is defined by the American National Standards Institute (ANSI) C84.1 (ANSI 2020), but voltage transients and temporary overvoltages are excluded from the scope. These phenomena are typically high-magnitude, short-duration voltage peaks, which are often referred to as a spike or a surge. Overvoltages can cause electrical faults and degrade the insulation of distribution equipment. Because of the often random nature of overvoltage, it is very difficult to characterize overvoltage phenomena observed in power systems. Often, statistical approaches are applied to characterize the overvoltage duration, magnitude, and effect. An overvoltage incident can be identified in the system if the line-to-line or line-to-ground voltage exceeds the maximum acceptable limit for the installed equipment. Depending on the voltage shape and duration, overvoltage can be broadly categorized into three groups (ABB 2019; Martinez-Velasco 2019):

\footnotetext{
${ }^{5}$ The current distortion requirements in IEEE Std 1547-2018 were written such that DERs are not responsible for distortions that result from background voltage harmonics that might exist prior to installation.

${ }^{6}$ Interharmonic components are not integer multiples of the power frequency (i.e., $60 \mathrm{~Hz}, 120 \mathrm{~Hz}, 180 \mathrm{~Hz}$ ) (IEEE 2014).
} 
1. Power frequency continuous overvoltage: Power frequency continuous overvoltages are observed for a duration of more than 1 minute with a root-mean-square magnitude of greater than 1.1 per unit. These overvoltage conditions are mainly caused by inadequate voltage regulation, the impact of reactive power compensation, or DERs on the network. Sustained overvoltage caused by DERs is mainly influenced by feeder impedance and the difference between local load and DER generation (Ghasemi and Parniani 2016).

2. Temporary overvoltage or swells: An abrupt change in large load in the network can cause a temporary overvoltage with a duration less than 1 minute. Temporary overvoltages are the most common power quality event and are difficult to prevent.

3. Transient overvoltage: According to IEC 60071-1, transient overvoltages are very short overvoltage conditions lasting a few milliseconds or less and are mainly caused by switching events in the network or lightning strikes (IEC 2019).

Figure 2 shows illustrative examples of waveforms for different overvoltage phenomena. It has been observed that DERs in power systems can cause overvoltage problems (Nelson et al. 2015; Ropp et al. 2017). Utilities have expressed concern especially about temporary overvoltages caused by inverter-based DERs (Nelson et al. 2015). Inverter-based DERs can cause two types of temporary overvoltages: (1) load rejection overvoltage (LRO) and (2) ground fault overvoltage (GFO). LRO can occur immediately after an islanding incident where the islanded section of the network contains more PV generation than load. Under such a scenario, before the inverters detect an islanding condition and the inverter controller takes corrective action, temporary overvoltages could occur in the islanded portion of the electrical network. On the other hand, GFO can occur in a four-wire circuit experiencing a single-line-to-ground fault while being energized by an ungrounded energy source, such as an ungrounded inverter (Ropp et al. 2017). 


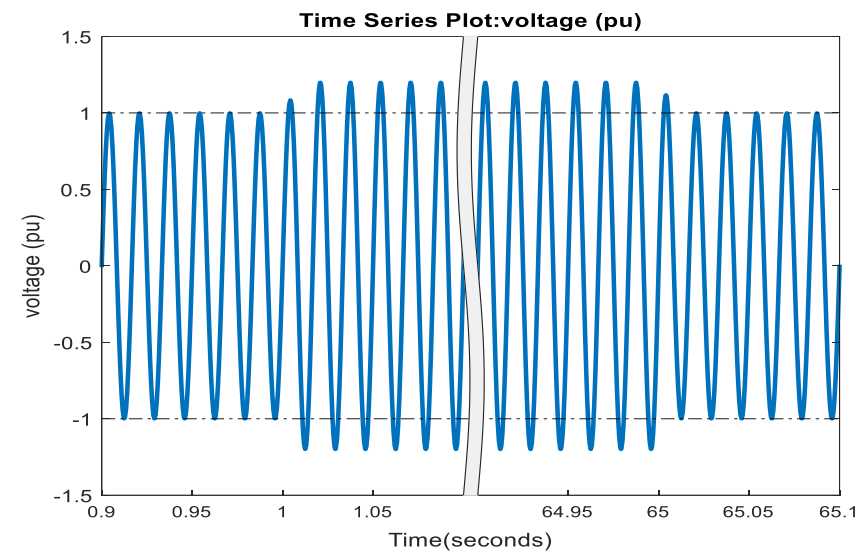

a. Power frequency continuous overvoltage

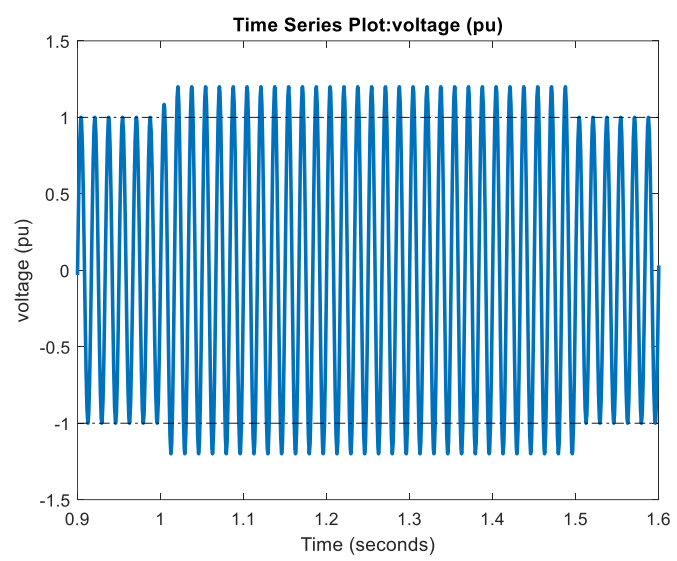

b. Temporary overvoltage

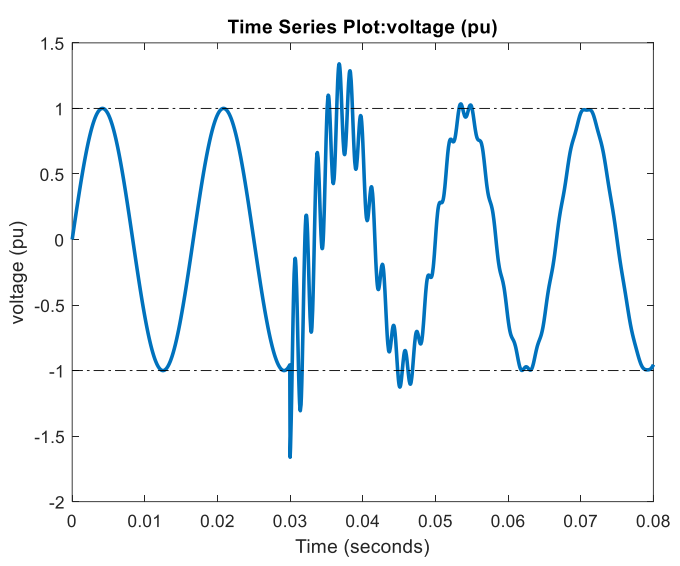

c. Transient overvoltage

Figure 2. Illustrative examples of different overvoltage phenomena observed in power systems

IEEE Std 1547-2018 addresses two different classes of temporary overvoltage: short duration and long duration. For longer duration overvoltages, the limitations are addressed in Clause 6 of IEEE Std 1547-2018 and reflect the nominal voltages stated in ANSI C84.1. Protective trip settings - to coordinate with the withstand capabilities of customer and utility equipment - are covered in IEEE Std 1547-2018 and discussed in a separate module of this educational series. ${ }^{7}$

Two short-duration overvoltage phenomena are of particular relevance to DER interconnection and power quality: GFO and LRO. Generally, both potentially manifest following the isolation of a distribution fault when a utility feeder is disconnected from the substation source and the DERs continue energization (i.e., island). The potential for overvoltage depends on the characteristics of the DERs, the presence of any external ground sources, and the characteristics of the load remaining connected to the island.

GFO is power quality problem that is a function of the transformer connection (line-to-line or line-to-neutral) and feeder impedances. GFO is more likely to occur if the DERs energizing the

\footnotetext{
${ }^{7}$ See https://www.nrel.gov/grid/ieee-standard-1547/educational-materials.html.
} 
island are synchronous generators rather than inverter-based DERs, unless supplemental protective grounding equipment is located on the feeder. Justification for supplemental grounding (e.g., grounding transformers) is often based on conventional fault analysis techniques in which DERs are modeled as ideal positive-sequence voltage sources in series with an impedance and loads are typically ignored. This representation could lead to highly inaccurate estimates of GFO for inverter-based DERs. This approach could also lead a utility to install supplemental ground sources that can negatively impact feeder protection coordination and lead to power quality issues (Whisenant 2016).

If a utility feeder is islanded with DERs that are operating at an output level that substantially exceeds load demand in the islanded system, LRO can occur because of the constant-current nature of typical DER inverters. Overvoltages caused by this phenomenon can be quite high (they can approach twice the nominal voltage), but they are generally of very short duration. The contribution of DERs to instantaneous or fundamental frequency overvoltage is permissible within the range shown in Table 2 according to IEEE Std 1547-2018.

Table 2. Maximum Allowed Overvoltage Contribution by DERs

\begin{tabular}{llll}
\hline & $\begin{array}{l}\text { Maximum } \\
\text { Overvoltage }\end{array}$ & Duration & Other Conditions \\
\hline $\begin{array}{l}\text { Fundamental frequency } \\
\text { line-to-ground voltage }\end{array}$ & $138 \%$ of nominal value & $\begin{array}{l}\text { One fundamental } \\
\text { frequency period }\end{array}$ & $\begin{array}{l}\text { Designed to operate } \\
\text { effectively grounded }\end{array}$ \\
$\begin{array}{l}\text { Fundamental frequency } \\
\text { line-to-line voltage }\end{array}$ & $138 \%$ of nominal value & $\begin{array}{l}\text { One fundamental } \\
\text { frequency period }\end{array}$ & \\
\hline
\end{tabular}

Additional requirements regarding cumulative overvoltage are also specified and illustrated with the help of Figure 3 in IEEE Std 1547-2018. The cumulative duration is calculated for a time window of 1 minute and the summation of overvoltage durations within that minute.

IEEE Std 1547-2003 does not address the overvoltages produced by this phenomenon in any way. In contrast, the limits in IEEE Std 1547-2018 provide the basis for protecting the utility and its customers. Overvoltage contribution limits are set by the manufacturer per the specified requirements. No parameters can be modified.

\subsection{Injection}

DC injection is a power quality issue exacerbated by the use of power electronic converter-based technologies in the grid. Many pieces of equipment and systems in the grid are highly susceptible to DC current. Distribution transformers in particular can be extensively damaged because of the DC current component (Buticchi and Lorenzani 2013). DC current flow into the distribution transformer creates an asymmetric magnetic core saturation that eventually results in overheating and power loss. The maximum allowed DC injection by different devices is limited by respective regulations, and power electronic converter-based devices often have dedicated control strategies and compensation schemes to minimize DC injection to the grid.

Section 7.1 in IEEE Std 1547-2018 specifies a threshold of $0.5 \%$ of rated full current for the maximum allowed DC injection by DERs. The threshold of allowed DC injection is applicable at 
the reference point of applicability. DC current injection limits are set by the manufacturer per the specified requirements. No parameters can be modified.

\subsection{Electromagnetic Interference}

One major disadvantage of power electronic-based converters used in power systems is the high level of electromagnetic interference (EMI) emissions produced during the high-frequency switching of certain components in power electronic converters (Jin and Weiming 2006). If it is too high, interference from EMI emissions can cause problems in the operation of nearby sensitive equipment and loads. Standards and regulations limit the acceptable EMI emissions level to protect other sensitive equipment and systems. Sensitive equipment can sometimes be designed to have special shielding from EMI interference when deployed in situations with a potential for high EMI exposure. There are different designs of EMI filters-both active and passive - to reduce the EMI emissions from power electronic converters.

For electric field strengths greater than $30 \mathrm{~V} / \mathrm{m}$, DERs are expected to comply with the related industry standards, including IEEE Std C37.90.2 and IEC 61000-4-3. If field strength is less than or equal to $30 \mathrm{~V} / \mathrm{m}$, however, then the DERs are expected to maintain the status or operation without any negative effect resulting from the EMI. An important IEEE guide regarding EMI is IEEE Guide--Adoption of IEC/TR 61000-3-7:2008, Electromagnetic compatibility (EMC)-Limits--Assessment of emission limits for the connection of fluctuating installations to MV, HV and EHV power systems (IEEE 1453.1-2012). 


\section{Power Quality Test Requirements}

\subsection{Distributed Energy Resource Type Tests}

Type tests ${ }^{8}$ are to be performed or overseen by a testing agency (e.g., UL). There is not a section per se on power quality type tests in the testing standard (IEEE 2020). Instead, associated tests are organized by power quality phenomena (e.g., DC injection) and are performed to verify compliance with the limit(s) specified in IEEE Std 1547-2018 (IEEE 2018).

\subsection{Distributed Energy Resource Evaluation and Commissioning Tests}

Clause 8 in IEEE Std 1547.1-2020 provides recommendations ${ }^{9}$ for DER evaluation and commissioning at installation, and Section 8.2.3.4 provides recommendations specifically for power quality.

Test equipment used for the Commissioning Test CT4 (power quality) shall comply with IEC 61000-4-30 Class A (i.e., capable of measuring AC, DC, root mean square, instantaneous, and harmonic content of the voltages, currents, and frequency). Using the prescribed measurement equipment, measurements should be performed on the DER unit, operated under the following conditions:

1. "During startup of the DER unit, energize the step-up transformers. Observe the impact on the energization in-rush current to the area EPS.

2. Turn on the DER unit and sweep the active and reactive power from 0 to the available capacity at the time of the test.

3. Perform a disconnect event that causes a step change in power delivery (not a soft shutdown-i.e., ramp down of power). Observe the impact to the area EPS" (IEEE 2020).

${ }^{8}$ IEEE Std 1547-2018 defines type test as "[a] test of one or more devices manufactured to a certain design to demonstrate, or provide information that can be used to verify, that the design meets the requirements specified in this standard" (IEEE 2018).

${ }^{9}$ IEEE Std 1547.1-2020 recognizes that there can be wide variation among DER installations and EPS conditions, and Clause 8 allows for this variation by providing recommendations instead of requirements. This flexibility allows for more or less verification, depending on the circumstances. 


\section{Conclusion}

Nearly all issues regarding the power quality behavior of individual DERs are well covered by IEEE Std 1547-2018 and are verified as part of the certification process (IEEE 2020 and UL$1741 \mathrm{SB}$ ); however, certain requirements, such as RVC and flicker limits, can depend on the grid strength ${ }^{10}$ at the point of connection and cannot be verified by individual inverter testing.

Likewise, the potential for incompatibilities with local loads affecting voltage quality depends on site-specific characteristics. These are examples of power quality integration concerns brought up by IEEE Std 1547-2018 but addressed during utility interconnection procedures, studies, and screens.

Table 3 is based on educated speculation on how different power quality parameters could be affected by IEEE Std 1547-2018-compliant DERs (Enayati 2018).

Table 3. How Different Power Quality Parameters Can Be Affected by IEEE Std 1547-2018

\begin{tabular}{|c|c|c|}
\hline Inverters & With & How? \\
\hline \multirow{3}{*}{ Are likely to help: } & Entering service & Expect better ramp rate and frequency control. \\
\hline & $\begin{array}{l}\text { Immunity to voltage } \\
\text { sags }\end{array}$ & $\begin{array}{l}\text { New ride-through requirements could reduce the } \\
\text { number of trips. }\end{array}$ \\
\hline & $\begin{array}{l}\text { Avoiding high or low } \\
\text { voltage at PCC }\end{array}$ & $\begin{array}{l}\text { Expect volt/volt ampere reactive and other reactive } \\
\text { power support modes to improve voltage regulation at } \\
\text { the PCC, especially when coordinated with other } \\
\text { voltage control elements on the feeder. }\end{array}$ \\
\hline \multirow[t]{2}{*}{$\begin{array}{l}\text { Could lead to new } \\
\text { incompatibilities: }\end{array}$} & $\begin{array}{l}\text { Harmonic current } \\
\text { distortion }\end{array}$ & $\begin{array}{l}\text { Higher-order harmonics-up to } 20 \mathrm{kHz} \text { from inverter } \\
\text { switching—-sometimes appear as resonances in } \\
\text { special circumstances. Prediction of these issues by } \\
\text { modeling is difficult. }\end{array}$ \\
\hline & $\begin{array}{l}\text { Communication } \\
\text { interference }\end{array}$ & $\begin{array}{l}\text { Lack of immunity to EMI could result in failures to } \\
\text { communicate. }\end{array}$ \\
\hline
\end{tabular}

\footnotetext{
${ }^{10}$ Generally, grid strength is characterized by the sensitivity of voltage to active and reactive power change. Voltage in a strong grid will be fairly constant under different power flow conditions.
} 


\section{Additional Resources}

Annex G of IEEE Std 1547-2018 provides additional information, general principles, and the approach related to power quality. The technical background on the selection of different requirements for power quality, the measurement of power quality-related quantities, basic explanations, and power quality issues experienced in the field are discussed in Annex G. This annex also frequently refers to other standards as references. Table 4 lists the other standards used to explain different power quality issues.

Table 4. Relevant Standards for Power Quality Issues

\begin{tabular}{ll}
\hline Power Quality Topic & Other Relevant Standards \\
\hline RVC limits & IEC 61000-4-30:2015, IEC 61000-3-7, \\
& IEEE Std 1453-2015 \\
Flicker limits & IEC 61000-3-7, IEEE Std 1453, IEC 61400-21, \\
& IEC 61000-4-15 \\
Current distortion limits & IEEE 519, IEEE Std 1547-2003 \\
Limitation of overvoltage & IEEE Std C62.92.6 \\
Electromagnetic interference & IEEE Std C37.90.2, IEC 61000-4-3 \\
Monitoring power quality (definitions) & IEEE Std 1159-2019 \\
\hline
\end{tabular}




\section{References}

ABB. 2019. Technical Note 2.0: Overvoltages-Origin and Magnitudes. Zurich, Switzerland. https://search.abb.com/library/Download.aspx?DocumentID=1HC0138870\&LanguageCode=en \&DocumentPartId=\&Action=Launch.

American National Standards Institute (ANSI). 2020. C84.1: Electric Power Systems and Equipment-Voltage Ratings (60 Hz). New York, NY.

Buticchi, Giampaolo, and Emilio Lorenzani. 2013. "Detection Method of the DC Bias in Distribution Power Transformers." IEEE Transactions on Industrial Electronics 60 (8): 353949. https://doi.org/10.1109/TIE.2012.2226418.

Dougherty, Jeff G., and Wayne L. Stebbins. 1997. "Power Quality: A Utility and Industry Perspective." Presented at the IEEE Annual Textile, Fiber and Film Industry Technical Conference, 1-10. https://doi.org/10.1109/texcon.1997.598528.

Electric Power Research Institute (EPRI). 2018. "IEEE Standard 1547TM Power Quality Considerations for Distributed Energy Resources.” Palo Alto, CA.

Enayati, Babak. 2018. Impact of IEEE 1547 Standard on Smart Inverters. Piscataway, NJ. PESTR67-r1.

Ghasemi, Mohammad Amin, and Mostafa Parniani. 2016. "Prevention of Distribution Network Overvoltage by Adaptive Droop-Based Active and Reactive Power Control of PV Systems." Electric Power Systems Research 133: 313-27. https://doi.org/10.1016/J.EPSR.2015.12.030.

Hawaiian Electric. 2021. "Power Quality Problems.” Accessed August 16, 2021.

https://www.hawaiianelectric.com/electrical-services/power-quality/power-quality-problems.

International Electrotechnical Commission (IEC). 2008. IEC Technical Report TR 61000-3-7 "Electromagnetic Compatibility (EMC) - Part 3-7: Limits - Assessment of Emission Limits for the Connection of Fluctuating Installations to MV, HV and EHV Power Systems. Geneva, Switzerland.

- 2019. IEC 60071-1:2019 - Insulation Co-ordination - Part 1: Definitions, Principles, and Rules. Geneva, Switzerland.

Institute of Electrical and Electronics Engineers (IEEE). 2014. IEEE Std 519-2014 - IEEE Recommended Practice and Requirements for Harmonic Control in Electric Power Systems. Piscataway, NJ.

- 2015. IEEE Std 1453-2015 - IEEE Recommended Practice for the Analysis of Fluctuating Installations on Power Systems. Piscataway, NJ.

2018. IEEE Std 1547-2018 IEEE Standard for Interconnection and Interoperability of Distributed Energy Resources with Associated Electric Power Systems Interfaces. Piscataway, NJ. 
- 2019. IEEE Std 1159-2019 - IEEE Recommended Practice for Monitoring Electric Power Quality. Piscataway, NJ.

- 2020. IEEE Std 1547.1-2020 - IEEE Standard Conformance Test Procedures for Equipment Interconnecting Distributed Energy Resources with Electric Power Systems and Associated Interfaces. Piscataway, NJ.

Jin, Meng, and Ma Weiming. 2006. "Power Converter EMI Analysis Including IGBT Nonlinear Switching Transient Model." IEEE Transactions on Industrial Electronics 53 (5): 1577-83. https://doi.org/10.1109/TIE.2006.882009.

Martinez-Velasco, Juan A. 2019. Transient Analysis of Power Systems: A Practical Approach. Wiley-IEEE Press.

Nelson, Austin, Anderson Hoke, Sudipta Chakraborty, Michael Ropp, Justin Chebahtah, Trudie Wang, and Brian Zimmerly. 2015. "Experimental Evaluation of Load Rejection Over-Voltage from Grid-Tied Solar Inverters.” Presented at the 2015 IEEE 42nd Photovoltaic Specialist Conference (PVSC), 1-6. https://doi.org/10.1109/PVSC.2015.7356399.

Rahman, Shahinur, Masood Moghaddami, Arif I. Sarwat, Temitayo Olowu, and Mohammadsaleh Jafaritalarposhti. 2018. "Flicker Estimation Associated with PV Integrated Distribution Network." Presented at the SoutheastCon, St. Petersburg, Florida.

Ropp, Michael, Anderson Hoke, Sudipta Chakraborty, Dustin Schutz, Chris Mouw, Austin Nelson, Michael McCarty, Trudie Wang, and Adam Sorenson. 2017. "Ground Fault Overvoltage With Inverter-Interfaced Distributed Energy Resources." IEEE Transactions on Power Delivery 32 (2): 890-99. https://doi.org/10.1109/TPWRD.2016.2577884.

Shi, Xiaojie , Tom Key, and Aminul Huque. 2019. "Can Photovoltaic Plants Cause Voltage Flicker? - Field Measurement and Screening." Presented at the IEEE 46th Photovoltaic Specialists Conference (PVSC). Chicago, Illinois.

Walling, Reigh. 2017. "Revision of IEEE Standard 1547TM: Additional Topics." https://www.cooperative.com/topics/operations/Documents/tsieee1547pt4april2017.pdf.

Whisenant, Steven. 2016. System Neutral Grounding Considerations for Inverter-Interfaced Distributed Energy Resources. Piscataway, NJ. PES-TR21. 